\title{
Evaluating difference in the foreign language classroom: Teaching approaches, syllabus design and student reactions
}

\author{
Stephanie Houghton \\ University of Kitakyushu, 4-2-1 Kitagata, Kokura minami-ku, Kitakyushu, Japan 802-8577 \\ E-mail: houghton@kitakyu-u.ac.jp
}

\section{Introduction}

Foreign language learners do not necessarily have naturally occurring encounters with speakers of the target language and instead tend to be presented with cultural difference as a matter of course through teaching materials, culture expressed through the target language and perhaps through teacher stories. Various scholars (Allport 1954; Barna 1982:327; Brislin 1984, 1986; Hewstone and Giles 1986; Gudykunst and Hammer 1988; Kim and Gudykunst 1988) have asked how students should evaluate culture difference when it does arise and what guidance should be given by the teacher, bearing in mind how easy it can be to fall back on stereotypes and prejudice in the face of the unknown. What learning objectives can and should be set within teaching approaches that deal with the evaluation of cultural difference in foreign language education, and why? To date, I am not aware of any research that has specifically addressed these questions but detailed analysis of the relevant literature seemed to suggest the following three teaching approaches.

\section{Teaching Approach 1}

Teachers should train learners to adopt a non-judgemental stance towards difference and engage in intellectual empathy to take the perspective of others (Bennett 1993:60; Byram and Zarate 1994:29; de Bono 1990:95; Gudykunst 1998:232; Paul and Elder 2002:26).

\section{Teaching Approach 2}

Teachers should train learners to focus their attention squarely back on themselves to develop critical awareness of their own evaluative processes and biases to control them, but teachers should not try to change learner values (Byram 1997:43-44; Byram, Gribkova and Starkey 2002:36; Guilherme 2002:141-144).

\section{Teaching Approach 3}

Teachers should basically follow teaching approach 2 but should also aim to bring student values into line with democratic principles and human rights promoting social justice, changing them if necessary (Byram and Guilherme 2000:70, 76; Guilherme 2002:166, 207; Osler and Starkey 1996). 
In the research project that led to the issues raised in this paper, the research question and subquestions were stated as follows:

\section{General Research Question}

How should teachers manage the evaluation of difference in foreign language education?

\section{Specific Research Questions}

- What learning objectives can and should be set within teaching approaches dealing with the evaluation of cultural difference in foreign language education, and why?

- How far did each approach meet its own objectives?

- How far are the objectives viable?

- How far is the meeting of objectives desirable, and why?

The purpose of this paper is not to answer these research questions (which were addressed in the bigger project) but to focus on an overview of research and syllabus design, before presenting data illustrating common student reactions to the teaching approaches described above. (Readers are referred to Houghton 2007 and 2009 for further detail.)

\section{Research design}

In this section, I will present an overview of the study's research design. Three different teaching approaches have been identified related to the evaluation of difference. They were implemented over a nine-month period, in one academic year, in three different English language classes at a university in Japan. A complex, qualitative case study was conducted on the basis of action research that examined the development of critical cultural awareness in intercultural language education, following Yin's (2003) guidelines for case study research. A natural fit was established between the research project envisaged and action research models that bring theory-driven action to bear upon classroom practice, theory through reflection and systematic research enquiry (Blaxter, Hughes and Tight 2001:71; Cohen, Manion and Morrison 2000:183, 227; Creswell 2003:15; Hopkins 2002:42-47, 124; McDonough and McDonough 1997:22-23, 203-205, 214-215).

The main objects of research were three courses of study designed by myself, as teacherresearcher, which despite their important variations also shared a common core course that aimed to raise student awareness of their own cultural perspectives prior to exposing them to cultural difference in each other, asking them to respond in particular ways. Each class consisted of a group of twelve female Japanese students in their second year of university study with myself as teacher and researcher.

To make the study trustworthy, issues related to credibility, transferability, dependability and confirmability were carefully considered, following Lincoln and Guba's (1985) guidelines. To enhance credibility, researcher and teacher reflexivity were built into teaching approaches to overcome personal bias. Conceptual clarity was also maximized in research design. To increase transferability, the study was designed within McDonough and Shaw's (1993) notion of the shared framework common to all foreign language teachers. (See also McDonough and Shaw's (1993:5) depiction of the typical stages of planning a language programme, presented in Diagram 1 below.) The study was conducted over a prolonged period of time, focusing carefully on various human relationships within the group to develop conceptual depth and 
richness through thick description to convey detail and uncover generic features of the local context. To enhance dependability, contextual factors and theoretical perspectives were made explicit.

Diagram 1. The Typical Stages of Planning a Language Programme

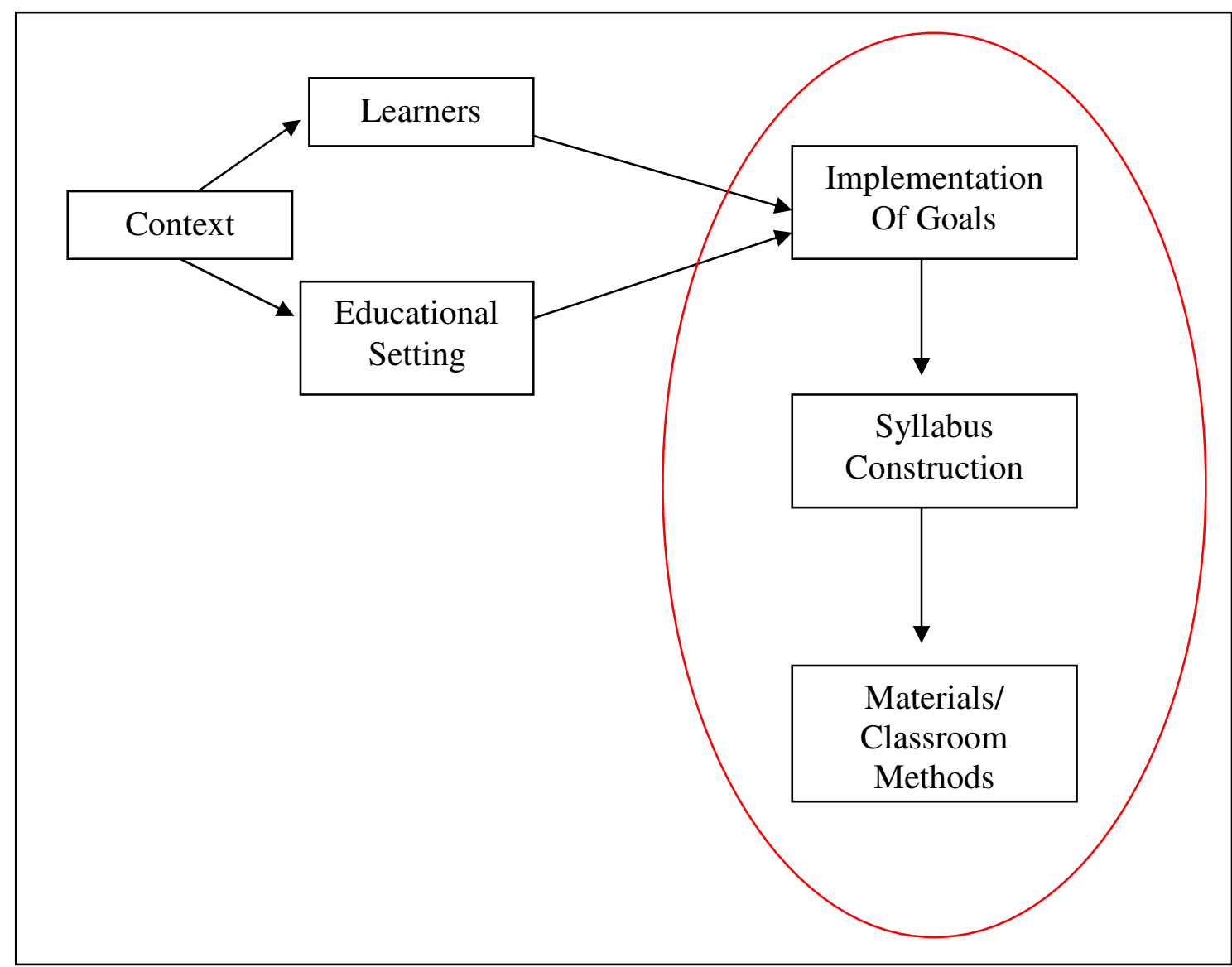

McDonough and Shaw (1993:5)

Data gathering and analysis procedures were laid out clearly enough so that they could be followed by others. Data collection techniques are presented in Table 1 below and the 5-step approach taken to data analysis (Hopkins 2002:130-139; Miles and Huberman 1994:57-76, 316; Glaser and Strauss 1999:57-71, 276-279; McDonough and McDonough 1997:124-125) is presented in Table 2. Confirmability was enhanced by gathering data from multiple sources, developing chains of evidence and employing forms of respondent validation where possible. Ethical issues related to research site access, selection of participants, informed consent, confidentiality, data ownership and disclosure were duly considered (Cohen et al. 2000:50-64; Creswell 2003:62-65; McDonough and McDonough 1997:68). 
Table 1. Data Collection Overview

\begin{tabular}{|c|}
\hline Stage 1: December 2002 - January 2003 \\
Courses were advertised \\
Students were sought, selected and divided into groups \\
\hline
\end{tabular}

\begin{tabular}{c}
\hline Stage 2: February- March 2003 \\
Pre-course questionnaires were administered \\
Interviews were conducted in English based on pre-course questionnaires \\
\hline
\end{tabular}

\begin{tabular}{|c|c|}
\hline Stage 3: April- July 2003 \\
Term 1 classes took place \\
Audio recordings were taken \\
Student coursework was gathered
\end{tabular}

\section{Stage 4: End of July 2003}

Mid-course group interviews (English/Japanese)

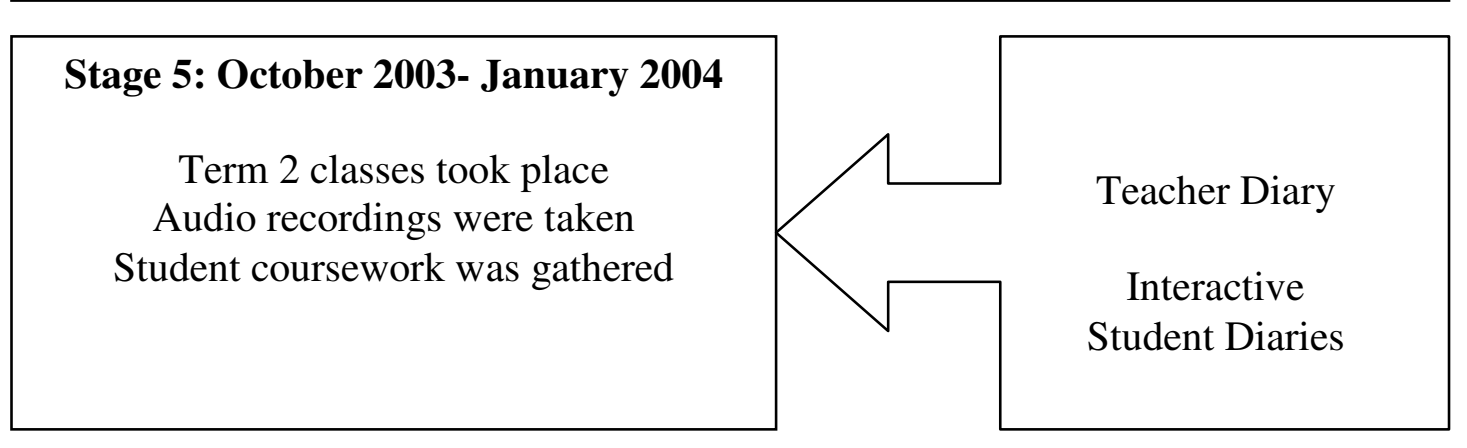

\section{Stage 6: End of January 2004}

End-of-course group interviews (English/Japanese) 
Table 2. The 5-step approach to data analysis

\begin{tabular}{|c|c|}
\hline Stage 1 & $\begin{array}{l}\text { Data were loaded into a single hermeneutic unit on the ATLAS programme and } \\
\text { organised into coded segments for easy retrieval. } \\
\text { Data were gathered to shed light on the extent to which individual learning } \\
\text { objectives had been met by students as they performed the tasks. }\end{array}$ \\
\hline Stage 2 & $\begin{array}{l}\text { The coding process was used to generate detailed description. } \\
\text { Emerging themes or categories, rooted in multiple perspectives and data } \\
\text { sources, were triangulated. }\end{array}$ \\
\hline Stage 3 & $\begin{array}{l}\text { The success of course-specific learning objectives was systematically } \\
\text { considered in relation to research questions in isolation, and presented } \\
\text { numerically in graphs. } \\
\text { Analytical descriptions of course-specific elements were drawn up, prioritising } \\
\text { student-generated data and highlighting student particularity. }\end{array}$ \\
\hline Stage 4 & $\begin{array}{l}\text { Analytical descriptions of course-specific elements were drawn up, prioritising } \\
\text { emic teacher-generated data and highlighting teacher particularity. }\end{array}$ \\
\hline Stage 5 & $\begin{array}{l}\text { Analytical descriptions from stages } 3 \text { and } 4 \text { were juxtaposed and amalgamated } \\
\text { ethically by the researcher taking everything into consideration. }\end{array}$ \\
\hline
\end{tabular}

\section{Syllabus design}

In this section, I will present an overview of the syllabus design undertaken as part of the current study. The three different teaching approaches drawn from the theoretical background set the parameters for the design of three different courses of English language study. They were each, however, rooted in a common "core course" that aimed to bring learner cultural values and perspectives to the surface as potential sources of perspective difference in a mono-lingual, mono-cultural classroom where the only non-Japanese research participant was the teacher (myself). The relationship between the core course and the three different teaching approaches is illustrated in Diagram 2 below. Although transformative critical evaluation can be considered an extension of critical evaluation, I coined the term "transformative critical evaluation" to clearly distinguish the course 3 approach from the course 2 approach. 
Diagram 2. Core Course and Teaching Approaches

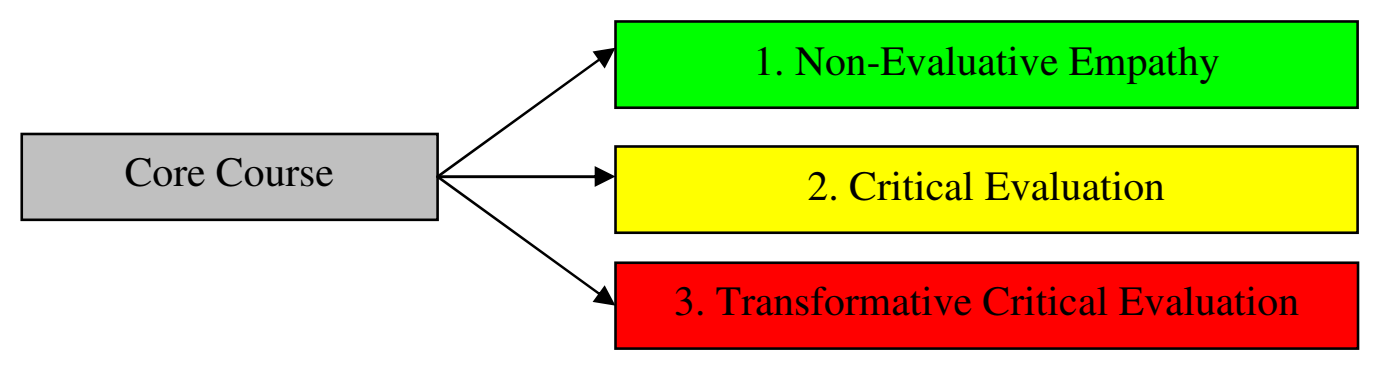

The three courses were spread over 2 terms of study, containing a total of 27 classes, conducted over a period of nine months from April 2003 to January 2004. All three courses ran through five interlocking stages, which each contained core course and course-specific components that sometimes overlapped. The overall interlocking course structure is illustrated in Diagram 3 below. As can be seen in Diagram 3, Stage 1 fed into Stages 2 and 3, which ran parallel to Stage 4(1). Stage 3 and Stage 4(1) both finished at the end of the first term in July. Stage 4(2) took the form of a summer assignment that fed into Stage 4(3) in the middle of the second term, between Stage 5(1) and Stage 5(2), around November.

Diagram 3. Interlocking Course Structure

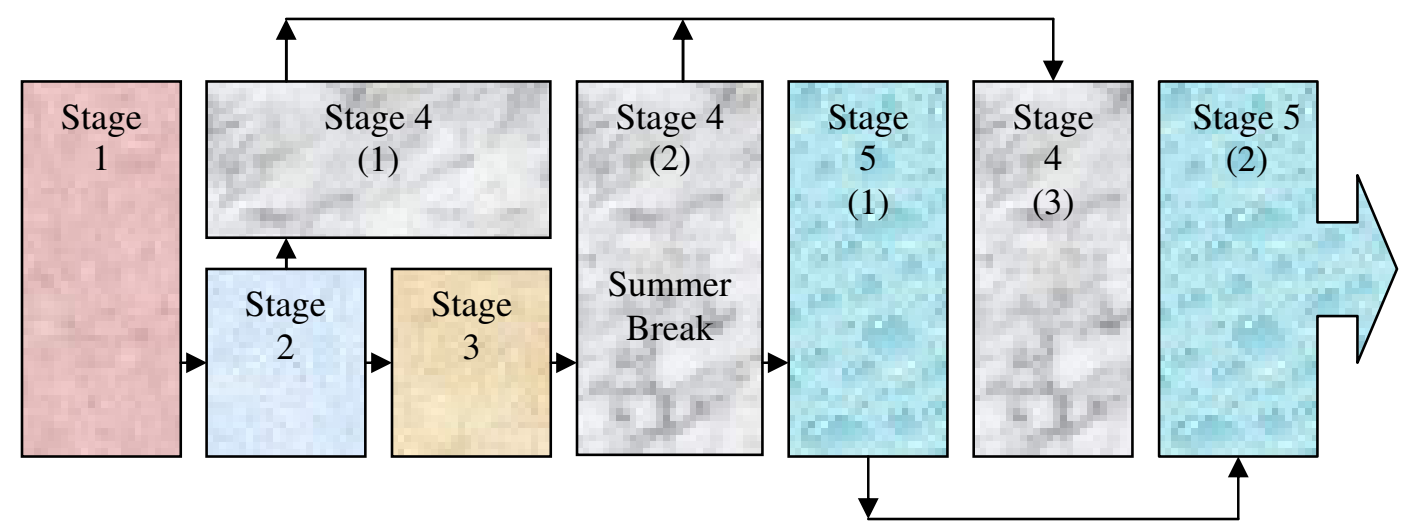

In Stage 1 (weeks 1-8), I provided a conceptual framework within which to raise learner cultural presuppositions (Lantolf 1999:31-32; Endicott, Bock and Darcia 2003; Byram 1989:107-108, 112-119; Fantini 1995; de Bono 1991:77-144) to the surface in working configurations to reveal perspective differences that we could work with later. Themes selected reflected the teacher's perceptions of underlying teacher and learner cultural difference and conceptual difference between the Japanese and English languages based on personal experience alone. Having distinguished values from beliefs and norms (Lustig and Koester 1999:30), the concept of values was broken down into more detail to set up a sufficient number of conceptual categories to reveal value difference between students. The taxonomy of ten universal value types, as set out in Schwartz and Sagiv (1995) and Schwartz, Verkasalo, Antonovsky and Sagiv (1997), was introduced to learners and various tasks were designed to promote learner self-reflection with reference to the same overarching conceptual 
framework of Stage 1. Having identified the values built into short dialogues, students were then asked to reflect on their own values and discuss them with reference to new topics that further expanded the conceptual framework. This would increasingly activate schemata prior to homework activities in which students had to write a series of four paragraphs reflectively describing their values with a view to presenting them to other students in the form of a speech in weeks 6-8. Students also made a value chart ranking the relative strength of their ten values on a scale from minus 5 to plus 5 .

With regard to course-specific components, course 1 tasks involved empathising using specific communication skills that would help learners construct accurate mental maps of speaker perspectives, whereas courses 2 and 3 involved learning the basic steps of critical evaluation by means of comparing, contrasting, judging and justifying judgements with reasons. In weeks 6-8, students had to employ these course-specific skills in various activities. Course 3 students went one step further, since I also aimed to change their values. I selected values from Schwartz and Sagiv's (1995) and Schwartz et al.'s (1997) value types that I considered more desirable for the purposes of intercultural communication and sought their agreement to a list of teacher-recommended target values for intercultural communication.

In Stage 2 (weeks 8-12), attempts were made to expose all learners to value difference before asking them to respond in course-specific ways. Having identified areas of value difference between learners by juxtaposing their value charts, I paired them up and focused their attention on particular differences. I asked them to imagine a potential problem that might be caused by the value difference and to write a short dialogue to illustrate it. When learners presented their dialogues to the class, other learners were asked to respond in course-specific ways. A third student was then placed into some pairs to mediate conflict in course-specific ways, prior to reflecting upon the activities in follow-up essays. In Stage 3 (weeks 11-14), learner attention was focused on conceptual difference that can cause misunderstanding considering (a) words or concepts that exist in Japanese but not in English, or vice versa, and (b) words that exist in both languages but have different meanings in the two languages. Drawing on personal experience, I wrote conflict dialogues rooted in both conceptual and value difference which learners had to respond to and mediate in course-specific ways.

Stage 4 (weeks 2-25) was divided into three sub-stages. In sub-stage 1 (weeks 2-14), students had to write three questions for each of Schwartz et al.'s ten value types, developing a questionnaire with which to interview a foreigner about their values (for the summer assignment) before responding in course-specific ways. This central task was enveloped by sub-stage 2 (week 14, summer assignment and week 15) when the Stage 3 discussion of concept was extended to include stereotypes as a particular kind of concept used to categorise people. Whilst week 14 activities focused on defining and examining the nature of stereotypes, week 15 focused on whether or not student stereotypes had been broken by their foreign interviewees. Students were asked to write reflective essays on group interviews held at the end of term 1 , in week 15 homework tasks.

In sub-stage 3 (weeks 23-25), students had to present their course-specific summer assignments to other students in speeches, responding in course-specific ways. Students were also set a number of other tasks during Stage 4 within which previous work was recycled back into the course to promote further reflection and discussion of student-generated themes. In some cases, student views expressed in homework or the interactive student dairy were presented to other students for comment. An end-of-course assignment was also set towards 
the end of Stage 4 in which students were given recordings of their pre-course interviews (March 2003) to transcribe before writing a reflective essay on how their ideas had developed or changed during the course. Students were also asked to submit discussion points for the end-of-course group interviews (January 2004).

Stage 5 (week 16-week 27) was structured around Hofstede's (1980) four dimensions of value difference: power distance, individualism/collectivism, masculinity/femininity and uncertainty avoidance. Having learned to identify the values in dialogues and video clips, learners were asked to respond in course-specific ways before mediating conflict dialogues rooted in value and concept difference between Japanese and English. In week 18, course 3 students branched off further to focus on democracy as a political system, comparing and contrasting their definition with other students' before considering possible incompatibilities between aspects of Japanese culture and democratic society suggested by the teacher. Course 3 students were asked to evaluate not with reference to their own values as in course 2 but with reference to universal values contained in the International Convention for the Elimination of Racial Discrimination (I.C.E.R.D.) and the Convention for the Elimination of Discrimination Against Women (C.E.D.A.W.), prior to conducting a democratic citizenship project by taking social action to help a minority group, following the example set by the teacher as role-model.

\section{Data interpretation}

In this section, I will present data that illustrate common student reactions to the teaching approaches described above, starting with teaching approach 1. Some students seemed to think that empathy was a viable skill but students also sometimes showed that they had failed to empathise effectively with interviewees, by injecting themselves into written accounts of interviewee values, comparing and contrasting interviewee values and ideas with their own, and sometimes judging. When students empathised with their partners verbally in class, teacher guidance was sometimes needed as students judged, or allowed their own ideas to intrude, although satisfactory descriptions were achievable in the end. Whether or not students found it easy to empathise seemed to depend partly on the degree of similarity and difference between self and other. This is a possible interpretation of Excerpt 1 below.

\section{Excerpt 1: Student B9: Week 15 Homework 2}

Many students said it is hard to empathize if someone else has very different values. And it is easy to empathize with people who have similar ideas to ourselves but harder when the person has very different ideas. Of course, I agree with these suggestions.

Whilst some students claimed it was easy to empathise with similar others because it was easy to imagine what they were thinking, this may have indicated that their perspectives were in play during empathy, and students may have later come to suspect that they may have been mistaking the opinions of similar others for their own. Also, prior knowledge appeared to facilitate empathy, although this may indicate that student concepts were being utilised rather than suspended. Whilst empathy was generally recognised to be an important communication skill, helping people get to know each other better by clarifying ideas and developing detail and accuracy, some students also felt that they were sinking under the influence of others as can be seen in Excerpt 2 below. 


\begin{abstract}
Excerpt 2: Student B1: Week 15 Homework 2
Somehow, easy or difficult it is, empathy is useful especially to improve our communication skills. If we consider other's side and try to understand their opinion or position, we can remove the cultural gap or some kind of misunderstanding. On the other hand, to empathy too much is sometimes dangerous a little bit I think. How is it so? Because I think sometimes people who give priority empathy tend to change their opinion and sink in a strong people who have a big influence. So before we use empathy, we have to treasure our culture, mind, value, nationality and belief.
\end{abstract}

The problem seemed to lie in some students confusing their opinions with those of others when they were trying to empathise with others by suspending their own values and concepts as instructed by the teacher. They sometimes felt shocked at the ideas of others and changed their minds in response, especially if they lacked confidence in their own opinions, as can be seen in Excerpt 3 below.

\title{
Excerpt 3: Student B9: Week 24 Homework 1
}

I sometimes feel admiration for students who has solid opinion and reasons which was very persuasive. At the same time, I get some shock. And I can't tell my own opinion. At that time, certainly I get big influence from that person. But it's important to have own opinion even if I was affected by others.

Other students, however, thought it was not possible to be influenced if they had empathised properly, claiming that effective empathy was precisely what held their own ideas intact as they interacted with others. They took influence as evidence of failure to empathise properly. Some students suggested that judging follows empathy and involves influence. These points are addressed in Excerpts 4 and 5 below.

\section{Excerpt 4: Student B7: Week 23 Homework 1}

When we talk to other person, firstly we empathise their opinion; next we judge it in our mind using our perspective and others perspective. Then it leads new opinion. So I think to treasure a lot of culture and mind and so on is useful for empathy, but to change our opinion and sink is a strong people who have to a big influence is related other process of our mind.

\section{Excerpt 5: Student B11 Week 24 Homework 1}

I think if I could suspend my values and ideas completely, they would not be influenced by the partner. When they are suspended, they are in another room from the partner's opinion. So, they won't be influenced. But we change our opinion sometimes. So, as student B7 said, changing our opinion is other process of our mind.

In course 2, some students claimed they did not want to judge because people generally have trouble understanding themselves since they are not sure what they think. Some students claimed that judging can undermine accurate understanding of the perspectives of others, prioritising information-gathering over judging. In course 2, an important link between information-gathering and judging surfaced when students were critically evaluating each other's speeches on values in weeks 6-8. Information-gathering was found to be necessarily partial insofar as the identification of key points through information-gathering involved selection of some points and rejection of others. Whether or not students managed to complete the critical evaluation task within the time limit set in class depended upon whether or not 
they had written enough information in the form of key points on the critical evaluation worksheet. If not, they could not complete the task because they could not remember the content of the speeches after class. If information-gathering takes place whilst people are trying to empathise with others and is also a pre-requisite for judging, empathy must precede judgement.

\section{Excerpt 6: Student A8 Week 15 Homework}

When I missed to hear and note other's presentation, to recall them was so difficult and more, it was serious, because I had to compare and judge them later. I thought I could not say anything when I don't grasp it, because my statement may make someone uncomfortable and give misunderstandings.

However, course 1 students exhibited many reactions to tasks that required them to empathise with their partner (such as listening to their partner and then describing their partner's perspective accurately enough for their partner to endorse) and the researcher was surprised by students' introduction of discussion points after the summer assignment speeches. Student B8, for example, shifted her reactions into a post-speech discussion point, indicating that she wanted to change in response to her interviewee. In course 1 , the discussion points absorbed time that had been set aside for listeners to empathise with speakers, which happened because the listeners started to analyse the content of the speeches to make sense of it, rather than trying to empathise with the speaker as instructed by the teacher. The identification of discrepancy within the self was also common, as students identified discrepancies between their stated value and behaviour, their stated value and ideal/hope, perhaps feeling bothered by the gap. Also, within a given value, students sometimes evaluated some aspects of it positively and other aspects of it negatively. This seemed to place students in a position to select between their own conflicting values.

\section{Excerpt 7: Student B5: Winter Assignment \\ I found the reason in a gap between my ideal values and my actual values. In my mind, I want to shift to my ideal one, so gradually I have been shifting to it. For example, in my ideal value chart, self-direction was plus 4, but in a reality, I couldn't decide something by myself, and I completely depended on others when I decide something. But now, I strongly think I want to decide my life by myself. Actually, I decided to go Britain alone and stay there about for 4 weeks in this spring vacation and I made reservation for it before saying to my parents.}

In course 3, the identification of discrepancy following analysis forms a common thread. Students were supposed to critically evaluate their own values with reference to target values. Through consciousness-raising, and having gotten used to the approach over time, students sometimes identified discrepancies between (a) their own current and target values, or (b) their stated values and their actual behaviour. They sometimes accepted the discrepancy and at other times felt disturbed by the gap. Sometimes, they resolved to develop themselves and expressed the inclination to change later (see Excerpt 8 below), perhaps starting to evaluate with reference not to their own values but to the target values instead.

\section{Excerpt 8: Student C6: Week 10 Homework 1}

I'm not weak to go around with strange people, but I don't like to do and I don't care about them. But this attitude is disadvantage for intercultural communication, I think... I hope to challenge new things on the other hand I'm afraid to meet new things. 
I don't think my opinion is bad, but I should have a bigger view. I think it helps me to communicate with strange people.

Even requests for clarification of certain speech parts sometimes seemed to cause conceptual reclassification in the speaker. Classification seemed to underpin judging insofar as concepts could be split into component parts and evaluated separately: students who claimed they could not judge points made by the speaker because they could see both good and bad points, found that they could judge quite clearly if they broke the concepts contained in the points made by the speaker down into smaller component parts through conceptual analysis - see Excerpt 9 below. Confusion seemed to be a common product not only of the clash of classification systems, but also of the clash of teacher and student logics as the teacher drew student attention to inconsistencies in their lines of reasoning.

\begin{abstract}
Excerpt 9: Student A5: Week 24 Student Diary
I learned from my speech today. I said I cannot judge or cannot say good or bad about universalism first. But after finishing my speech, by being asked about it, I could make my idea and judge very clearly. However I use 'cannot judge good or bad' in the mean which I said after my speech so I just didn't write it down. That's why I think this is not unconscious value. I was aware of it before ... I admit that there are two kinds of definition in the word. One is rough definition and another is precise definition. So, as you wrote, we should select them depends on situations. Precise definition was used in our class, as you said we should split words into small parts to judge. So, I think this is precise definition. Rough definition is general way of use. I mean, in our daily life, we use words without thinking its definition well.
\end{abstract}

In course 3, the teacher actively and consciously tried to change student values, sometimes apparently succeeding. However, if such students were simply accepting the view of the teacher in contrast with students who continued to disagree with the teacher's view even in the face of authority pressure, the course 3 teacher wondered which should be considered more pedagogically desirable. Student C3 from course 3 noticed the intentional application of pressure by the teacher and claimed that being handicapped by having to communicate in a foreign language prompted student value change as the teacher not only supported student self-expression in English but also pressured students to say things they did not really mean. Further, she claimed that course 3 students gradually came to accept the teacher's opinion unconsciously - see Excerpt 10 below.

\title{
Excerpt 10: Student C3: End-of-Course Interview (Japanese Interviewer) \\ We are handicapped to speak English because English is not our mother tongue. (The teacher) led us to what we want to say under real consideration of our situation. But I thought she sometimes led us to what she wanted to listen under expectation. I really appreciate her to cover our language disadvantage. I could learn the phrase and how to construct the sentence. But when I was urged to say something by her under expectation, the opinion strayed a little from what I really wanted to say. And unconsciously I came to admit the other opinion.
}

Let us now consider what seemed to be the by-products of student analysis of other students' viewpoints. Meta-cognitive and meta-affective awareness seemed to surface as students consciously compared and contrasted self and other, noting their own tendencies in response to others. Students noticed that (a) they tended to seek differences instead of similarities, (b) 
they felt at ease when they identified similarities, or (c) identifying differences highlighted particular aspects of their own distinct character. However, there were many negative reactions to critical evaluation and to judging in particular, although some concerns about judging were alleviated when the definition of critical evaluation and reasons for doing it was discussed in more detail. But later in the course, critical evaluations were sometimes left incomplete as students seemed to avoid judging, perhaps even hiding, as they critically evaluated others. However, some students also seemed to get used to analysing their own judging tendencies, noting the emotional underpinnings of their evaluative processes. As they gradually identified their standards, they later developed strategies for judging better, perhaps taking ideals as guiding principles, which involved refining the definition and purpose of critical evaluation in terms of clarifying thought, situations, ideal society and self with mediation being identified as one part of the process. In this regard, see Excerpt 11 below.

\section{Excerpt 11: Student A1: Week 15 Homework}

Second, about judge, at the beginning, I don't like judging, because I felt that I was a rude person by deciding others good or bad. However after I analyzed my judging tendency, I could be getting used to it little by little. In first semester, I hadn't found my standard for judging yet, so my judging depended on my feeling, whether I felt good or bad. It was so simple. However I think the hint to get the standard for judging was hiding, because I wrote in my diary "I judged differences positively if I can agree with them." It means if the differences are reasonable or good, I can accept them. In $2^{\text {nd }}$ semester, thanks to (the teacher), I could get the word of "ideal" as my key word for judging.

Student A8 from course 2, who had initially rejected the idea of judging when instructed by the teacher to vocalise her judgements of the viewpoints of other students, gradually came to see critical evaluation as an unpleasant but necessary step towards mutual understanding between people from different cultures. She emphasised the need to explore why people react in certain ways because she realised how this could prevent barriers forming. When critically evaluating others in public, however, she felt terribly shocked. Ultimately, student A8 seemed to want to hide her honest opinions out of concern for the negative evaluations others would have of her. Finally, she concluded that whilst she recognised the importance of expressing judgement, she thought it needed to be done with care. Students might have remained divided in this way with respect to their opinion of judging and critical evaluation right through to the end of the course because of possible underlying Japanese tendencies, according to some students. For example, some students identified the Japanese value of social harmony (known as "wa" ( $\square$ ) in Japanese) as an important aspect of communication in Japan, which discourages the vocalisation of (particularly negative) judgement, and some students may have dropped out of course 3 because they found it too painful to judge so openly - see Excerpt 12 below.

\footnotetext{
Excerpt 12: Student C3: End-of-Course Interview (Japanese Interviewer)

I am not going to judge eternally, even though I learned the way to judge through this course. I'm not good at judging anything anyway. Especially I'd not like to judge whether it is good or bad toward culture, people, and historical things in my life although I sometimes need to judge. In fact, those who felt painful dropped out of this course. The Japanese conception, 'wa', in other word, 'harmony' is indeed beautiful. We don't have to be westernized by denying such a beautiful conception. The point is that even though we try to become cosmopolitans, it is wrong to deny the way with
} 
agony, which Japanese have cultivated so far. I am not going to introduce the way to judge everything into my life. All of things have both good and bad elements. We can argue a lot against Westerns who judge such Japanese as indecisive people.

Despite this possible cultural resistance to judging, an important by-product of this controversial discussion about judging seemed to be an increase in meta-cognitive awareness, as students started to notice and describe their various judgemental tendencies to others. As students became familiar with the judgemental tendencies of others through ongoing discussion, personal approaches towards critical evaluation gradually surfaced, although discussion of this kind seemed to require greater English language ability because of the abstract nature of the concepts referred to during discussion. Identifying their own tendencies, and a range of possible other tendencies generated by others, seemed to place students in a position to consciously select from them. Positivity emerged as a selected tendency in some students whilst others chose to make both positive and negative judgements in recognition of the fact that they were not always right, associating negative self-evaluation with selfenhancement or attempting to increase honesty, fairness, self-knowledge or bias-reduction by considering both positive and negative aspects before reconsidering their position, rejecting emotional judgement. Yet other students seemed to prioritise flexibility over the taking of a clear position required in critical evaluation.

\section{Conclusions}

Since foreign language learners tend to be presented with cultural difference as a matter of course, questions arise as to how students should evaluate culture difference when they are faced with it and what guidance should be given by the teacher in this respect. These questions were considered in relation to three theoretically driven teaching approaches that were investigated through a case study based on action research. The study was conducted at a Japanese university with thirty-six research participants split into three groups of twelve each. The teaching approaches implemented systematically over one academic year were described as follows:

\section{Teaching Approach 1}

Teachers should train learners to adopt a non-judgemental stance towards difference and engage in intellectual empathy to take the perspective of others.

\section{Teaching Approach 2}

Teachers should train learners to focus their attention squarely back on themselves to develop critical awareness of their own evaluative processes and biases to control them, but teachers should not try to change learner values.

\section{Teaching Approach 3}

Teachers should basically follow teaching approach 2 but should also aim to bring student values into line with democratic principles and human rights promoting social justice, changing them if necessary.

In this paper, I presented an overview of the study's research and syllabus design, before presenting data illustrating common student reactions to the teaching approaches described above. The main patterns that were found for each teaching approach are summarised below. 
With regard to teaching approach 1, some students seemed to think that empathy was a viable skill but when students empathised with their partners verbally in class, teacher guidance was sometimes needed as students judged, or allowed their own ideas to intrude, although satisfactory descriptions were achievable in the end. Whether or not students found it easy to empathise seemed to depend partly on the degree of similarity and difference between self and other, and prior knowledge appeared to facilitate empathy as students made use of existing information in their minds. Whilst empathy was generally recognised to be an important communication skill, some students also felt that they were sinking under the influence of others, perhaps because they confused their opinions with those of others or felt shocked at the ideas of others and changed their minds in response, especially if they lacked confidence in their own opinions. Other students, however, took influence as evidence of failure to empathise properly and some students suggested that judging follows empathy and involves influence.

With regard to teaching approach 2, some students claimed they did not want to judge others because people are generally unsure what they think, perhaps prioritising informationgathering over judging. However, information-gathering was found to be necessarily partial as it involved the selection of some points over others, which may be hampered by a lack of time undermining the evaluation process later. It was concluded that if information-gathering takes place whilst people are trying to empathise with others and is also a pre-requisite for judging, empathy must precede judgement. However, when students in course 1 were instructed to empathise with their partner (for example, listening to their partner and then describing their partner's perspective accurately enough for their partner to endorse, which prioritised information-gathering), they often tried to analyse and discuss points made by the speaker instead of just empathising, which absorbed class time unexpectedly. The identification of discrepancy within the self was also common, as students identified discrepancies between their stated value and behaviour, their stated value and ideal/hope, sometimes feeling bothered by the gap. Also, within a given value, students sometimes evaluated some aspects of it positively and other aspects of it negatively. This seemed to place students in a position to select between their own conflicting values.

With regard to teaching approach 3, the identification of discrepancy commonly resulted from analysis as students identified discrepancies between (a) their own current and target values, or (b) their stated values and their actual behaviour, which often triggered change in students. Even requests for clarification of certain speech parts sometimes seemed to cause the reclassification and re-evaluation of concepts and sub-concepts in speakers, which seemed to underpin and influence judgement processes. Confusion seemed to be a common product not only of the clash of classification systems, but also of the clash of teacher and student logics as the teacher drew the students' attention to inconsistencies in their lines of reasoning. In course 3, the teacher actively and consciously tried to change student values, sometimes apparently succeeding, but the pedagogical value of this was brought into question for various reasons.

When performing critical evaluations, meta-cognitive and meta-affective awareness seemed to develop as students consciously compared and contrasted self and other, noting their own tendencies in response to others. However, there were many negative reactions to this process (some of which may have been cultural in nature), although some students also seemed to get used to analysing their own judging tendencies, recognising the emotional underpinnings of their evaluative processes and the standards they were applying when passing judgement, 
which provided opportunities for conscious self-development and, ultimately, the acceptance of an unpopular teaching approach by some students.

\section{References}

Allport, G. 1954. The nature of prejudice. New York: Macmillan.

Barna, L.M. 1982. Stumbling blocks in intercultural communication. In L. Samovar and R. Porter (eds). 1984. Communication between cultures. Belmont, California: Wadsworth. pp. 322-330.

Bennett, M. 1993. Towards ethnorelativism: A developmental model of intercultural sensitivity. In R.M. Paige (ed.) Education for the intercultural experience. University of Michigan: Intercultural Press, inc. pp. 21-72.

Blaxter, L., C. Hughes and M. Tight. 2001. How to research. Oxford: Oxford University Press.

Brislin, R.W. 1984. Prejudice in intercultural communication. In L. Samovar and R. Porter (eds). Intercultural communication: A Reader. Belmont, California: Wadsworth. pp. 354358.

Brislin, R.W. 1986. Prejudice and intergroup communication. In W. Gudykunst (ed.) Intergroup communication. London: Edward Arnold. pp. 74-85.

Byram, M. and G. Zarate. 1994. Definitions, objectives and evaluation of cultural competence. Strasbourg: Council of Europe.

Byram, M. 1989. Cultural studies in foreign language education. Clevedon, England: Multilingual Matters.

Byram, M. 1997. Teaching and assessing intercultural communicative competence. Clevedon, England: Multilingual Matters.

Byram, M., B. Gribkova and H. Starkey. 2002. Developing the intercultural dimension in language teaching. A practical introduction for teachers. Strasbourg: Council of Europe.

Byram, M. and M. Guilherme. 2000. Human rights culture and language teaching. In A. Osler (ed.) Citizenship and democracy in schools: Diversity, identity, equality. Stoke-on-Trent: Trentham Books.

Cohen, L., L. Manion and K. Morrison. 2000. Research methods in education. London: Routledge Falmer.

Convention for the Elimination of All Forms of Discrimination against Women. Downloaded from http://www.un.org/womenwatch/daw/cedaw/.

Creswell, J.W. 2003. Research design: Qualitative, quantitative and mixed method approaches. Thousand Oaks, California: Sage Publications.

de Bono, E. 1970/1990. Lateral thinking. London: Penguin Books.

de Bono, E. 1991. I am right you are wrong. London: Penguin Books.

Endicott, L., T. Bock and N. Darcia. 2003. Moral reasoning, intercultural development and multicultural experiences: Relations and cognitive underpinnings. International Journal of Intercultural Relations 27(4): 403-419.

Fantini, A. 1995. Introduction - Language, culture and worldview: Exploring the nexus. International Journal of Intercultural Relations 19: 143-153.

Glaser, B. and A. Strauss. 1967/1999. The discovery of grounded theory: Strategies for qualitative research. Chicago, Ill.: Aldine de Gruyter.

Gudykunst, W. 1998. Bridging differences: Effective intergroup communication. Thousand Oaks, California: Sage Publications.

Gudykunst, W. and M. Hammer. 1988. Strangers and hosts: An extension of UR theory. In Y. Kim and W. Gudykunst (eds). Cross-cultural adaptation. Beverly Hills: CA: Sage. 
Guilherme, M. 2002. Critical citizens for an intercultural world: Foreign language education as cultural politics. Clevedon, England: Multilingual Matters.

Hewstone, M. and H. Giles. 1986. Social groups and social stereotypes in intergroup communication: A review and model of intergroup communication breakdown. In W. Gudykunst (ed.) Intergroup communication. London: Edward Arnold Publishers. pp. 1026.

Hofstede, G. 1980. Culture's consequences: International differences in work-related values. London: Sage Publications.

Hopkins, D. 2002. A teacher's guide to classroom research. Oxford: Oxford University Press.

Houghton, S. 2007. Managing the evaluation of difference in foreign language education: A complex case study in a tertiary level context in Japan. Unpublished Ph.D. thesis, Durham University, UK.

Houghton, S. 2009. Managing the evaluation of difference in foreign language education: A complex case study in a tertiary level context in Japan. Ph.D. dissertation, University of Durham (United Kingdom), England. Retrieved 30 October 2009 from Dissertations \& Theses: A\&I. (Publication No. AAT 3347260). Document URL: http://proquest.umi.com/pqdweb?did=1771527591\&Fmt=6\&clientId=79356\&RQT $=309 \&$ VName $=$ PQD.

International Convention for the Elimination of All Forms of Racial Discrimination. Downloaded from http://www.ohchr.org/english/law/pdf/cerd.pdf.

Kim, Y. and W. Gudykunst. 1988. Theories in intercultural communication. Newbury Park: Sage.

Lantolf, J. 1999. Second culture acquisition: Cognitive considerations. In E. Hinkel (ed.) Culture in second language teaching and learning. Cambridge: Cambridge University Press. pp. 28-47.

Lincoln, Y. and E. Guba. 1985. Naturalistic inquiry. Newbury Park, California: Sage Publications.

Lustig, M. and J. Koester. 1999. Intercultural competence: Interpersonal communication across cultures. New York, NY: Longman.

McDonough, J. and C. Shaw. 1993. Materials and methods in ELT: A teacher's guide. Oxford: Blackwell.

McDonough, J. and S. McDonough. 1997. Research methods for English language teachers. London: Arnold.

Miles, M. and A.M. Huberman, A. 1994. Qualitative data analysis: An expanded sourcebook. London: Sage Publications.

Osler, A. and H. Starkey. 1996. Teacher education and human rights. London: David Fulton.

Paul, R. and L. Elder. 2002. Critical thinking: Tools for taking charge of your professional and personal life. Financial Times Prentice Hall, Upper Saddle River, NJ: Prentice Hall.

Schwartz, S. and L. Sagiv. 1995. Identifying culture-specifics in the content and structure of values. Journal of Cross-Cultural Psychology 26(1): 92-116.

Schwartz, S., M. Verkasalo, A. Antonovsky and L. Sagiv. 1997. Value priorities and social desirability: Much substance, some style. British Journal of Social Psychology 36: 3-18.

Yin, R. 2003. Case study research: Design and methods. Thousand Oaks, California: Sage Publications. 